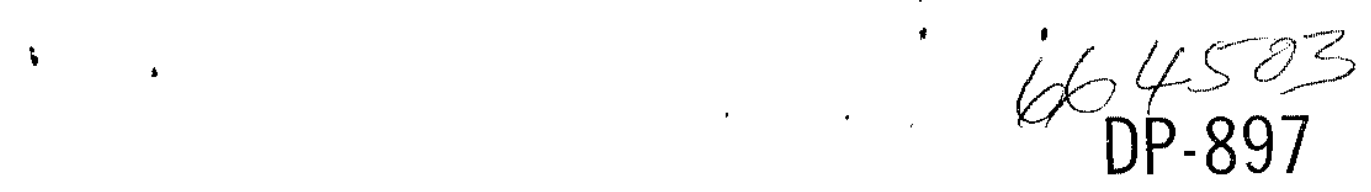

\title{
A VERSATILE ELECTRONIC TRIP DEVICE
}

W. J. WOODWARD
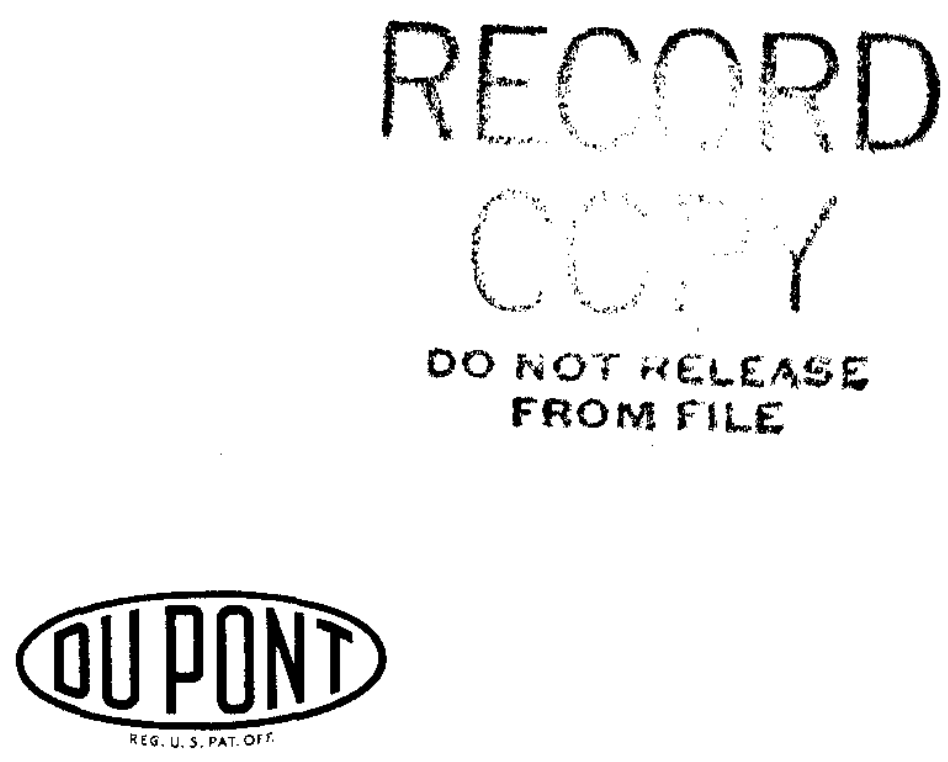

Savannah River Laboratory

Aiken, South Carolina 
This report was prepared as an account of Government sponsored work. Netther the United States, nor the Commission, nor any person acting on behalf of the Commission:

A. Makes any warranty or representation, expressed or implied, with respect to the accuracy, completeness, or usefuliness of the information contained in this report, or that the use of any information, apparatus, method, or process disclosed in this report may not infringe privately owned rights; or

B. Assumes any liabilities with respect to the use of, or for damages resulting from the use of any information, apparatus, method, or process disclosed in this report.

As used in the above, "person acting on behalf of the Commission" includes any employee or contractor of the commission, or employee of such contractor, to the extent that such employee or contractor of the Commission, or employee of such contractor prepares, disseminates, or provides access to, any information pursuant to his employment or contract with the Commission, or his employment with such contractor.

Printed in USA. Price $\$ 0.50$

Avallable from the office of Technical Services

U. S. Department of Cominerce

Washington 25, D. C. 


\section{3

Instruments

(TID-4500, 30th Ed.)

\section{A VERSATILE ELECTRONIC TRIP DEVICE}

by

W1111am J. Woodward

\section{Approved by}

D. E. Waters, Manager

Laboratory Operations and Services Division

June 1964

E. I. DU PONT DE NEMOURS \& COMPANY

SAVANNAH RIVER LABORATORY

AIKEN , SOUTH CAROLINA

CONTRACT AT (07-2) - I WITH THE

UNITBD STATES ATOMIC ENERGY COMMISSION 


\title{
A VERSATILE ELECTRONIC TRIP DEVICE
}

\begin{abstract}
A simple alarm trip unit was designed to operate from the recorder output voltage from a micro-microammeter without affecting recorders connected to the same terminals. The unit has a constantgain amplifier for millivolt signals, direct connections for higher level signals, a meter with a manually set trip contact, and fail-safe relay circuitry to operate associated reactor scram circuits.
\end{abstract}

\section{DISCUSSION}

Micro-microammeters are used to measure 1onization current in chambers placed in the neutron flux of experimental reactors. These micro-microammeters must provide maximum response speed at all operating power levels of the reactor for safety information, as well as for accurate flux measurements. Output voltages from these instruments can be used to operate recorders and may also be used to operate alarm trip circuits. The trip circult is a high-impedance load; therefore, the same instrument used for physical measurements can also serve as a safety device because the trip circuit will not affect recorders operating from the same terminals.

Because output voltage ranges from micro-microammeters vary, the electronic trip unit is designed to accept either of the two most common ranges--50 millivolts and 1 volt--and can be easily modified to accept others. The 50-millivolt signal must be amplified, and DC amplifiers inherently drift; therefore, an AC-coupled system w1th feedback is employed. The DC signal is converted to AC by a 60-cycle chopper. The amplifier output is then rectified and sent to the meter through a calibration network. For operation from the 1-volt signal the amplifier is bypassed, leaving the meter and callbration network connected to the micro-microammeter output. Selection of the proper mode of operation is assured, because the 50-millivolt micro-microammeter outputs are banana facks, and the 1-volt outputs are telephone plugs that bypass the ampl1fier when plugged into the jack on the trip unit chassis. 
Fall-safe operation is mandatory in reactor scram circults, so the trip relay is normally energized, maintalning a contact closure that will bring about a scram upon opening. This means that a power supply fallure, relay fallure, or relay removal (a plug-in type) will initiate a scram. The relay is de-energized by shorting its coil through the meter contacts when an upscale excursion exceeds the trip setting. The short circuit current then locks the meter contacts closed until a reset button is pressed. Encapsulated neon pilot lights indicate "power on" and "scram." The meter indication can be compared with that of the micro-microammeter for calibration and proper operation.

\section{DESCRIPTION AND OPERATION OF INSTRUMENT}

The electronic trip device is constructed on a standard 3-1/2" x 19" relay rack panel (Figure 1) with operating controls clearly identified. The meter has a linear 0-100 scale that makes correlation with the driving instrument relatively easy. Plug-in components, external connections, and cal1bration adfustments are at the rear of the chassis (Figure 2). The top and bottom are open for servicing and cooling (Figure 3).

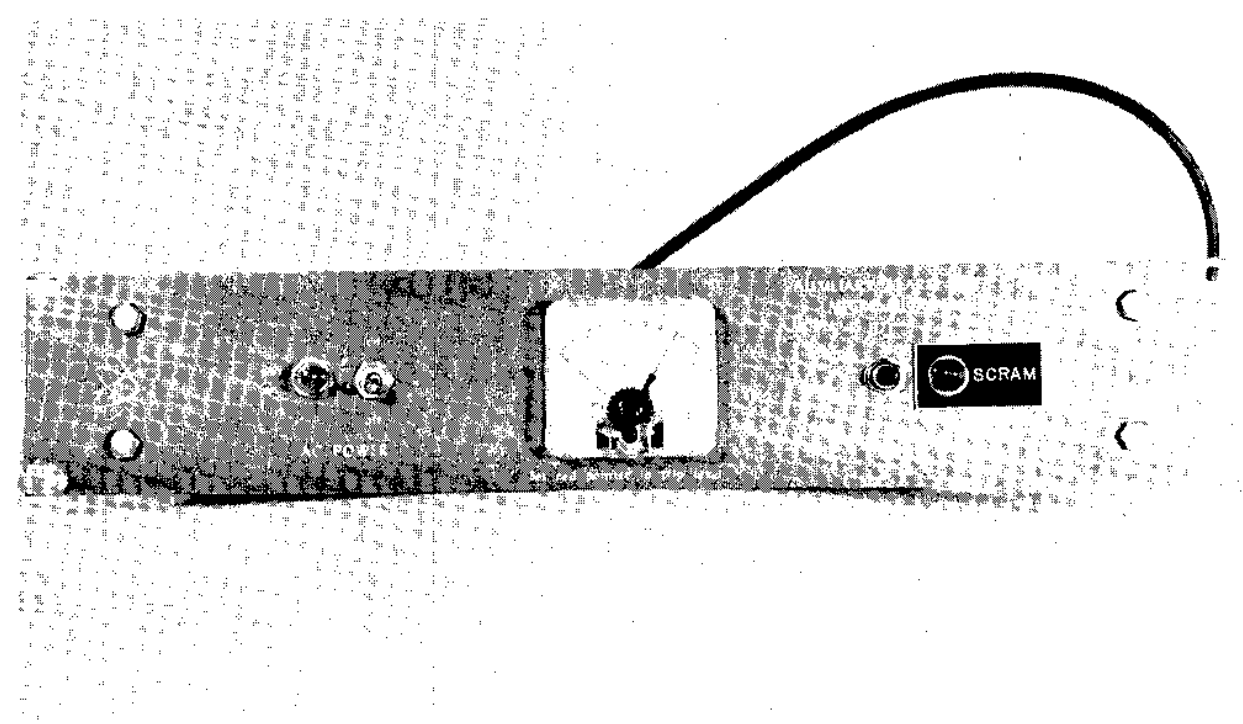

FIG. I FRONT PANEL 


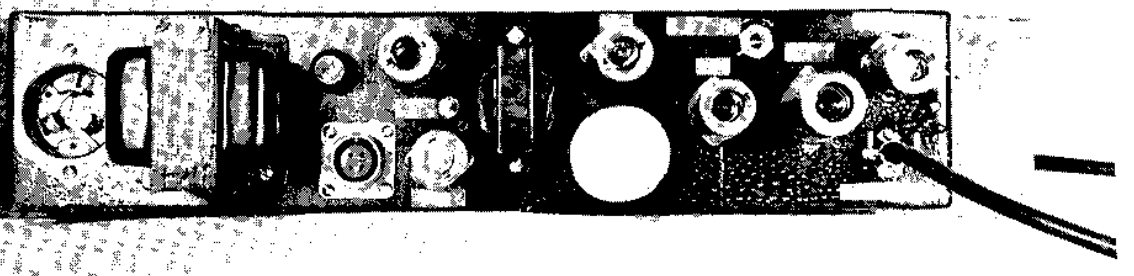

FIG. 2 REAR OF CHASSIS

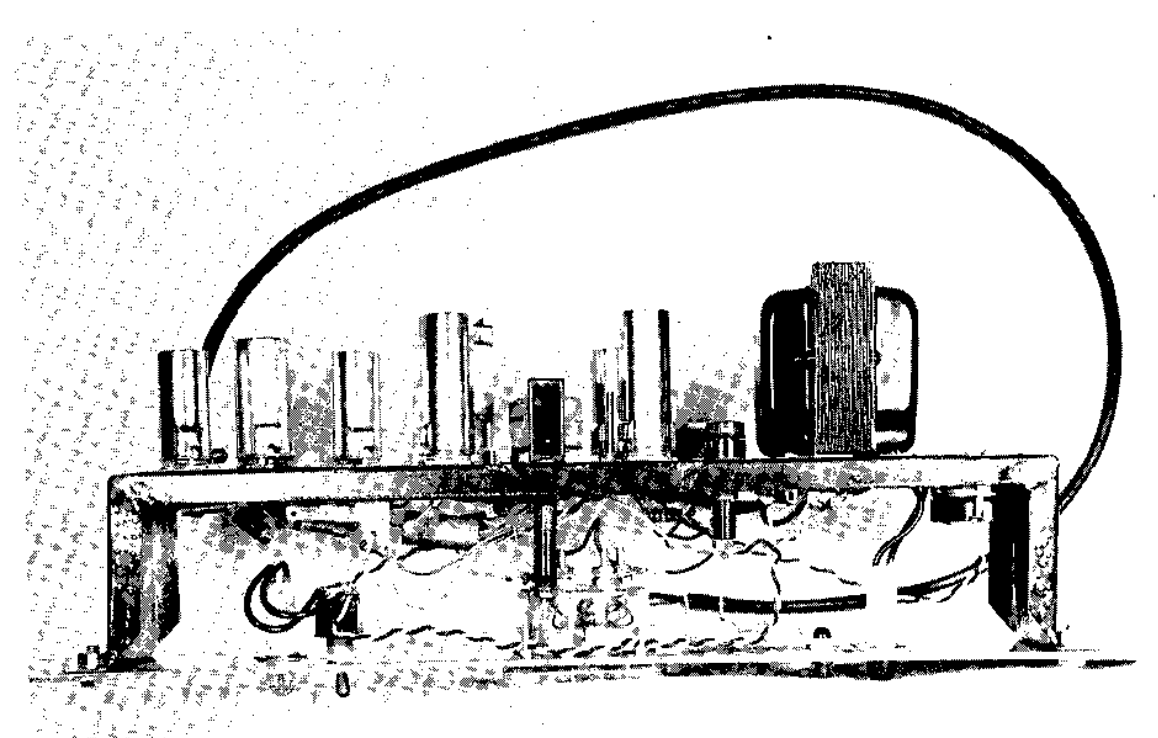

FIG. 3 TOP OF CHASSIS 
The instrument is operated from millivolt signals by connecting the input banana plugs to the signal source. As shown in Flgure 4, one of the plugs is grounded, and ground continuity must be observed rather than polarity. (Since the chopper makes an AC signal of the DC input, its polarity is Immaterial.) After the signal has been chopped into a 60-cps wave form, it is capacity coupled to the grid of Vla (Figure 4) for amplification. VIa and VIb comprise a two-stage voltage amplifier having an open loop gain of about 2000. The second-stage output is fed to a cathode follower (V2), where the cathode signal is capacity coupled simultaneously to the meter rectifier and a feedback loop. The feedback loop is a voltage divider formed of $1 \%$ precision resistors in a ratio of 1000:1, with the lower resistance arm acting also as the cathode bias resistor for the first stage. Thus, feedback limits the gain at the meter rectifler input to 1000 in spite of variations in tube parameters. The rectifled voltage obtained from the amplifier is applied to a 0-100 microampere DC meter through an adjustable calibration resistance consisting of a $1 \%$ precision fixed unit in series with a miniature composition potentiometer.

The DC microammeter is a contact-making type having an adjustable high-level contact with series locking co11. This means that the current flowing through the closed contacts also flows through an additional winding of the meter coil, and the current direction is chosen to increase the upscale deflection and maintain contact pressure. Normal operation is restored after a contact closure by pressing a reset button that momentarily interrupts the locking coll current and allows the contacts to open (provided meter current has decreased to a value below the contact setting). The meter contacts are connected in parallel with a relay coil, which is part of a voltage divider circuit. Ordinarily, the voltage across the relay maintains it in the energized state, but when the meter contacts are closed the relay coll is shorted, causing all of the voltage drop to appear across the remainder of the divider and the relay to become de-energized. External circuitry is connected so that the normally open contacts of the relay (closed during ordinary operation) are involved, making a fall-safe system possible. The fall-safe idea is carried a step further by obtaining the power for the external circult from the fused and switched input power of the instrument. Thus, any of the following will trip the alarm:

Power fallure to the instrument

Switching off the instrument

Power supply failure within the instrument, including removal of rectifier $\sqrt{3}$ or regulator tube V4 
Faliure of the relay coil

Removal of the relay (plug-in type)

Disconnection of the external trip c1rcuit

Upscale meter deflection exceeding the trip setting

Only a failure in the amplifier or actual meter circuit can occur without causing a trip, and the meter indication on the front panel permits continuous checking against these failures. To eliminate this inherent danger, higher output micro-microammeters may be connected directly to the meter circuit via a closed-circuit telephone jack, bypassing the amplifier completely. When this is done, signal polarity must be observed. Operating several alarm trip units simultaneously on one reactor further enhances the over-all safety of operation.

Several of these instruments have been operated for more than 3 years with a reactor at the Savannah River Laboratory. Operation has been satisfactory, and minimum maintenance has been required. Operation of 50-mv null-balance recorders has not been affected when a trip unt is connected in parallel.

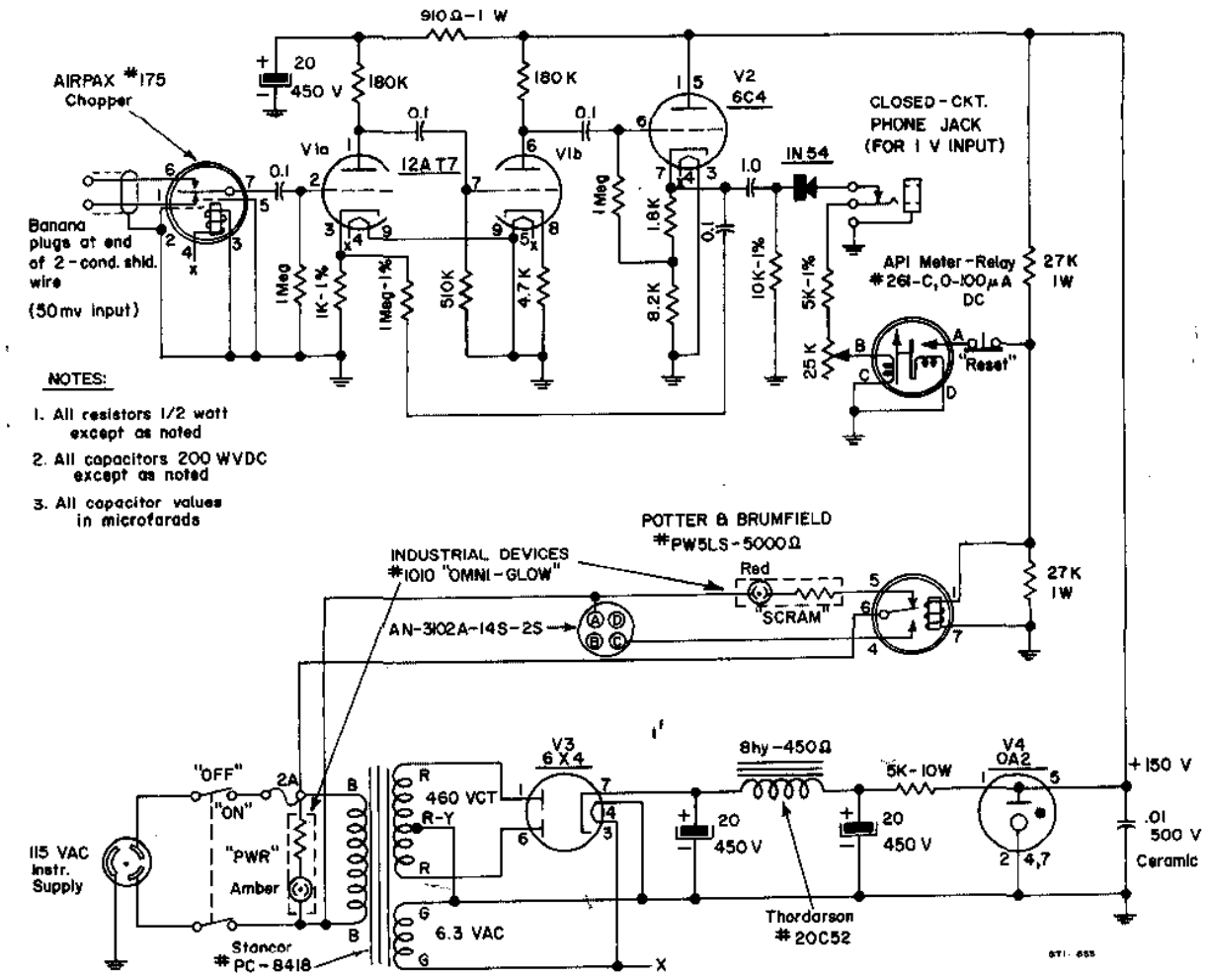

FIG. 4 SCHEMATIC DIAGRAM

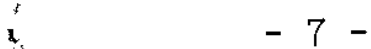

